\title{
Prediksi Indeks Prestasi Mahasiswa Yang Berkuliah Sambil Bekerja Di Universitas Advent Indonesia Dengan Menggunakan Metode Decision Tree C4.5 Dan SMOTE
}

\author{
Yusran Timur Samuel $* 1$, Chrystle Beatrix Allbright Nahuway ${ }^{2}$ \\ ${ }^{12}$ Fakultas Teknologi Informasi, Universitas Advent Indonesia \\ e-mail: ${ }^{* 1}$ y.tarihoran@unai.edu, ${ }^{2}$ chrystle.beatrix@gmail.com
}

\begin{abstract}
Abstrak
Pendidikan tinggi adalah salah satu cara agar mendapat pekerjaan lebih mudah, hal tersebut disebabkan karena melalui pendidikan individu tersebut mampu meningkatkan kualitas sumber daya manusia pada zaman ini. Namun biaya pendidikan yang tinggi sangat mahal sehingga individu yang ingin berkuliah harus juga bekerja di saat yang bersamaan, maka penelitian ini bertujuan untuk memprediksi indeks prestasi mahasiswa yang berkuliah sambil bekerja di Universitas Advent Indonesia. Dari hasil penelitian ini terdapat 8 atribut yang berpengaruh dalam memprediksi indeks prestasi mahasiswa di Universitas Advent Indonesia yaitu Departemen Pekerjaan, Jam Kerja, Jurusan, Jenis Kelamin, Tempat Tinggal, Usia, Jumlah SKS dan Indeks Prestasi. Metode yang digunakan dalam penelitian ini adalah Decision Tree C4.5 yang diimplementasikan pada program WEKA dengan algoritma J48. Penelitian ini juga menggunakan algoritma SMOTE (Synthetic Minority Oversampling Technique) untuk menyeimbangkan jumlah data pada kelas minor. Root teratas dari penelitian ini adalah Jenis Kelamin yang mempengaruhi indeks prestasi mahasiswa di Universitas Advent Indonesia. Algoritma SMOTE pada penelitian ini berguna untuk membantu menaikan hasil dari penelitian ini sebesar 7-8\% bisa dilihat dari hasil akurasi pengujian cross validation 10 folds adalah $63.6672 \%$, kemudian rata-rata hasil dari precision dan recall adalah 0.621 dan 0.637. Sementara untuk hasil akurasi dari split test 70:30 adalah $62.7955 \%$, kemudian rata-rata hasil dari precision dan recalladalah 0.621 dan 0.628 . Jika dibandingkan dengan penggunaan algoritma decision tree C4.5 saja maka, akurasi dari pengujian cross validation 10 folds adalah $55.5044 \%$, dengan rata-rata hasil dari precision dan recall adalah 0.545 dan 0.555 . Sementara hasil akurasi dari split test 70:30 adalah $55.2995 \%$ dengan rata-rata hasil dari precision dan recall adalah 0.554 dan 0.553 . Hasil analisa menggunakan confusion matrix serta kurva ROC dengan hasil dari 0.688 menjadi 0.756 , yang berada dalam rentang $0.70-0.80$ yang masuk kedalam tingkat diagnosa fair classification. Dapat disimpulkan bawa terdapat pengaruh berkuliah sambil bekerja yang cukup kuat terhadap indeks prestasi mahasiswa. Dengan urutan atribut dari yang paling atas adalah Jenis Kelamin, Jumlah SKS, Jurusan, Umur, Departemen Kerja, Jam Kerja dan Tempat Tinggal.
\end{abstract}

Kata Kunci: Data Mining, Decision Tree C4.5, SMOTE, Prediksi Indeks Prestasi, Berkuliah Sambil Bekerja.

\section{Predicting Student Grade Point Average Who Is Studying While Working At Adventist University Of Indonesia Using Decision Tree C4.5 Method And SMOTE}

\begin{abstract}
Higher education is one way to get job easier, this thing happens because through education the individual is able to increase the level of human resources in this era. However, the high cost of education is very expensive so individuals who wants to study must also work at the same time, so this research aims
\end{abstract}


to predict the student GPA who is studying while working at the same time at Adventist University of Indonesia. From the results of this research there are 8 attributes that have an effect on predicting student GPA at Adventist University of Indonesia, namely the Department of Work, Working Hours, Course, Gender, Residence, Age and Number of Credits. The method that has been used in this research is Decision Tree C4.5 implemented on the WEKA program with the 348 algorithm. This research also uses the SMOTE (Synthetic Minority Oversampling Technique) algorithm to balancing the amount of data in the minor class. The top root of this research is Gender which affects the student GPA at University of Indonesia. The SMOTE algorithm in this research is useful to help raising the result of this research by $7-8 \%$ can be seen from the results of the accuracy of the cross validation 10 folds test is $63.6672 \%$, the average result of precision and recall are 0.621 and 0.637 . While the accuracy of the split test $70: 30$ is $62.7955 \%$, then result of precision and recall are 0.621 and 0.628. When compared with the use of the Decision Tree C4.5 algorithm only, the accuracy of the cross validation 10 fold test is $55.5044 \%$, with the average result of precision and recall is -.545 and 0.555 . While the accuracy of the split test $70: 30$ is $55.2995 \%$ with the results of precision and recall is 0.554 and 0.553 . The analysis results using confusion matrix and ROC curve with results from 0.688 to 0.756 , which are in the range of $0.70-0.80$ which is included in the level of fair classification diagnosis. It can be concluded that there is a strong effect while working on the student GPA. With the order of attributes from the top most are Gender, Total Credit, Department, Age, Department of Work, Working Hours and Residence.

Keywords: Data Mining, Decision Tree C4.5, SMOTE, Predicting Student GPA, studying while working.

\section{Pendahuluan}

Kesempatan mendapatkan kerja akan lebih mudah didapat jika seorang pencari kerja mempunyai latar belakang pendidikan di Perguruan tinggi. Namun biaya untuk bersekolah di Perguruan tinggi tidak murah yang menyebabkan seorang mahasiswa yang berkuliah sambil bekerja. Motivasi mahasiswa untuk memilih bekerja paruh waktu disebabkan oleh banyak faktor antara lain: guna memenuhi kebutuhan keuangan yang mendesak, atau sekadar mengisi waktu luang, ingin mendapatkan pengalaman bekerja, ingin bertemu dengan banyak orang (meningkatkan ketrampilan 5 komunikasi), ingin meningkatkan ketrampilan dan keahlian dalam bekerja sehingga dapat meningkatkan karir di masa datang. Maka dari itu penulis ingin membuat penelitian ini untuk memprediksi IPK mahasiswa dan mengevaluasi proses pendidikan yang ada di Universitas Advent Indonesia berdasarkan data yang telah ada mengenai mahasiswa yang berkuliah sambil bekerja dan juga indeks prestasi mereka. Atribut yang akan dipakai di penelitian ini antara lain adalah jenis kelamin, SKS yang diambil, dan waktu bekerja yang diikuti akan dijelaskan lebih jelas di bab metode penelitian.

\section{Metode}

Data penelitian yang digunakan oleh penulis adalah data yang telah didata dan tersusun rapi oleh Pembantu Rektor II dan Biro Administrasi Akademik. Data yang telah diambil oleh penulis tentunya dapat di kelolah oleh penulis untuk mendapatkan hasil yang akurat saat melakukan prediksi terhadap mahasiswa yang berkuliah sambil bekerja di Universitas Advent Indonesia.

Dalam tahapan penelitian ini penulis menggunakan data-data dari database UNAI, yang dikumpulkan menjadi 8 atribut. Subyek yang diteliti oleh penulis adalah data-data mahasiswa dari tahun 2013-2017. Kemudian data-data yang telah dikumpulkan akan diolah dengan aplikasi WEKA menggunakan metode Decision Tree C4.5 atau algoritma 348 pada program WEKA.

\section{Tahapan Penelitian}

1. Mengumpulkan atribut yang akan digunakan pada saat pengelolaan data.

2. Melakukan pengumpulan data dari database yang dibutuhkan sesuai dengan atribut yang sudah ditetapkan di database Universitas Advent Indonesia. 
3. Cleaning data yaitu merapikan data-data yang tidak konsisten maupun data-data yang memiliki kekacauan yang harus dirapikan kembali agar data-data tersebut bias diproses. Dalam proses ini penulis menggunakan Microsoft excel dan diubah formatnya menjadi csV (comma separated values).

4. Dalam penelitian ini penulis menggunakan metode Decision Tree C.45 atau dalam aplikasi WEKA disebut juga Decision Tree J48.

5. Kemudian setelah itu data-data tersebut diproses menggunakan aplikasi WEKA.

6. Setelah melewati proses tersebut maka akan mendapatkan hasil dengan menggunakan metode Decision Tree C4.5 yang diuji dalam aplikasi WEKA.

Fungsi utama dari preprocessing data atau pemrosesan awal data terbagi menjadi beberapa bagian yaitu untuk membersihkan data yang tidak valid atau null maupun data-data yang bersifat tidak konsisten. Kemudian integrasi data langkah ini berguna untuk menggabungkan data-data dari berbagai tabel, file, kubus data atau file text lainnya ke dalam satu tabel. Selanjutnya adalah seleksi data yang berguna untuk menyeleksi data-data yang relevan dari tabel, file, kubus data maupun file text yang diperlukan. Langkah yang terakhir adalah transformasi data yaitu proses pengubahan data dan penggabungan data ke dalam bentuk yang dibutuhkan untuk melakukan operasi agregasi atau mengubah nilai.

[1] SMOTE atau (Synthetic Minority Oversampling Technique) adalah solusi mengatasi ketidakseimbangan data. Jika metode oversampling lainnya memperbanyak data secara acak maka metode SMOTE ini menambah jumlah data kelas minoritas agar setara dengan kelas mayoritas, data yang ditambah adalah data buatan menggunakan rumus penghitungan jarak Euclidean untuk menghitung data numerik, sementara untuk data kategori dihitung dengan rumus Value Difference Metric (VDM) yaitu:

$$
\Delta(\mathrm{X}, \mathrm{Y})=w_{x} w_{y} \sum_{\mathrm{i}=1}^{\mathrm{N}} \delta\left(x_{i}, y_{i}\right)^{r}
$$

Dengan:

$\Delta(\mathrm{X}, \mathrm{Y}) \quad$ : jarak antara amatan $\mathrm{X}$ dengan $\mathrm{Y}$

$w_{x} w_{y} \quad:$ botot amatan (dapat diabaikan)

$\mathrm{N} \quad$ : banyaknya perubah penjelas

$\mathrm{R} \quad$ : bernilai 1 (jarak Manhattan) atau 2 (jarak Euclidean)

$\delta\left(x_{i}, y_{i}\right)^{r} \quad$ : jarak antar kategori, dengan rumus:

$$
\delta\left(\mathbf{V}_{1}, \mathbf{V}_{2}\right)=\sum_{\mathrm{i}=1}^{\mathrm{n}}\left|\frac{\mathbf{C}_{1 \mathrm{i}}}{\mathbf{C}_{1}}-\frac{\mathbf{C}_{2 \mathrm{i}}}{\mathbf{C}_{2}}\right|^{\mathbf{k}}
$$

$$
\begin{array}{ll}
\delta\left(V_{1}, V_{2}\right)^{r} & : \text { jarak antara nilai } \mathrm{V} 1 \text { dan } \mathrm{V} 2 \\
C_{1 i} & : \text { banyaknya } \mathrm{V} 1 \text { yang termasuk kelas I } \\
C_{2 i} & : \text { banyaknya } \mathrm{V} 2 \text { yang termasuk kelas I } \\
\mathrm{I} & : \text { banyaknya kelas; } \mathrm{I}=1,2, \ldots, \mathrm{m} \\
C_{1} & : \text { banyaknya nilai } 1 \text { terjadi } \\
C_{2} & : \text { banyaknya nilai } 2 \text { terjadi } \\
\mathrm{N} & : \text { banyaknya kategori } \\
\mathrm{K} & : \text { konstanta (biasanya } 1 \text { ) }
\end{array}
$$

Dengan data yang akan dikumpulkan, penulis mencoba untuk menyelesaikan dengan menggunakan metode Decision Tree-J48 yang juga bisa disebut Decision Tree C4.5 dengan rumus di bawah ini. 


$$
\operatorname{Entropy}(S)=-p 1 \log 2 p 1-p 2 \log 2 p 2(2)
$$

Keterangan:

S : Himpunan kasus

pl : Proporsi dari sv terhadap S

Rumus Gain digunakan untuk mencari nilai keseluruhan dari Entropy, di bawah ini merupakan rumus untuk mencari Gain:

Keterangan:

$$
\text { Gain }(\mathrm{S}, \mathrm{A})=\operatorname{Entropy}(s) \sum_{\text {vevalues }(A)}^{n} \frac{s v}{s} * \operatorname{Entropy}(\mathrm{Sv})
$$

$S$ : Himpunan kasus

A : Atribut

$\mathrm{n}$ : Jumlah partisi atribut $\mathrm{A}$

sv : Jumlah kasus pada partisi ke $v$

$\mathrm{s}$ : Jumlah kasus dalam $\mathrm{S}$

\section{Hasil}

Tabel 1 Perbandingan Hasil Cross Validation

\begin{tabular}{|c|c|c|c|c|}
\hline Algoritma & Akurasi & Precision & Recall & ROC Area \\
\hline Decision Tree C4.5 & $55.965 \%$ & 0.549 & 0.560 & 0.676 \\
\hline SMOTE & $64.3143 \%$ & 0.629 & 0.643 & 0.770 \\
\hline
\end{tabular}

Dari perbandingan di atas algoritma Decision Tree C4.5 memliki hasil akurasi, precision, recall dan ROC Area yang lebih kecil dibandingkan dengan hasil cross validation menggunakan algoritma Decision Tree C4.5 dan algoritma SMOTE secara bersamaan. Algoritma SMOTE berguna untuk meningkatkan hasil akurasi dari $55.965 \%$ menjadi $64.3143 \%$, precision dari 0.549 menjadi 0.629 , recall dari 0.560 menjadi 0,643 dan ROC Area dari 0.676 menjadi 0.770.

Tabel 2 Perbandingan Hasil Precentage Split

\begin{tabular}{|c|c|c|c|c|}
\hline Algoritma & Akurasi & Precision & Recall & ROC Area \\
\hline Decision Tree C4.5 & $53.7634 \%$ & 0.521 & 0.538 & 0.664 \\
\hline SMOTE & $61.5622 \%$ & 0.595 & 0.616 & 0.750 \\
\hline
\end{tabular}

Dari Perbandingan percentage split di atas algoritma Decision Tree C4.5 memliki hasil akurasi, precision, recall dan ROC Area yang lebih kecil dibandingkan dengan hasil percentage split menggunakan algoritma Decision Tree C4.5 dan algoritma SMOTE secara bersamaan. Algoritma SMOTE berguna untuk meningkatkan hasil akurasi dari $53.7634 \%$ menjadi $61.5622 \%$, precision dari 0.521 menjadi 0.595 , recall dari 0.538 menjadi 0.616 dan ROC Area dari 0.664 menjadi 0.750 .

Urutan atribut ditetapkan oleh penulis melalui hasil penghitungan entropy dari hasil yang paling besar sampai kepada hasil yang penghitungan entropy yang paling kecil. Urutan atribut di bawah ini juga menunjukkan atribut mana yang paling berpengaruh terhadap indeks prestasi mahasiswa yang berkuliah sambil bekerja di Universitas Advent Indonesia:

1. Jenis Kelamin dengan hasil penghitungan yaitu entropy 0.8

2. Jumlah SKS dengan hasil penghitungan yaitu entropy 0.1

3. Jurusan dengan hasil perhitungan entropy yaitu 0.06 
5. Departemen Kerja dengan hasil perhitungan entropy yaitu 0.006

6. Umur dengan hasil perhitungan entropy yaitu 0.001

7. Jam Kerja dengan hasil perhitungan entropy yaitu 0.0017

8. Tempat Tinggal dengan hasil perhitungan entropy yaitu 0.0011

\section{Pembahasan}

\section{Pengujian menggunakan decision tree C4.5 tanpa menggunakan SMOTE}

(1) Accuracy

$$
\begin{array}{lrr}
\text { Correctly Classified Instances } & 1215 & 55.965 \\
\text { Incorrectly Classified Instances } & 956 & 44.035
\end{array}
$$

Gambar 1 Accuracy Cross Validation

Dari gambar di atas mengartikan bahwa data yang diklasifikasikan dengan benar adalah $55.965 \%$ sedangkan data yang diklasifikasikan secara tidak benar adalah $44.035 \%$.

(2) Confusion Matrix

$$
\begin{aligned}
& ===\text { Confusion Matrix }=== \\
& \begin{array}{rrrrl}
\text { a } & \text { b } & \text { c } & <-- \text { classified as } \\
150 & 63 & 324 & \text { a }=\text { HIGH } \\
52 & 255 & 273 & \text { b } & \text { b UNDER } \\
111 & 133 & 810 & \text { | } & \text { c }=\text { AVERAGE }
\end{array}
\end{aligned}
$$

Gambar 2 Confusion Matrix Cross Validation

Dari gambar confusion matrix 2 dapat dilihat bahwa:

a. 150 data High yang diklasifikasikan menjadi data High, 63 data High yang diklasifikasikan menjadi data Under dan 324 data High yang diklasifikasikan menjadi data Average.

b. 52 data Under yang diklasifikasikan menjadi data High, 255 data Under yang diklasifikasikan menjadi data Under dan 237 data Underyang diklasifikasikan menjadi data Average.

c. 111 data Average yang diklasifikasikan menjadi data High, 133 data Average yang diklasifikasikan menjadi data Under dan 810 data Average yang diklasifikasikan menjadi data Average.

(3) Precision Recall

$\begin{array}{ll}\text { Precision } & \text { Recal1 } \\ 0.479 & 0.279 \\ 0.565 & 0.440 \\ 0.576 & 0.769 \\ 0.549 & 0.560\end{array}$

Gambar 3 Precision Recall Cross Validation

Dari Gambar 3 dapat dijelaskan bahwa:

a. Precision dari data High adalah 0.479 yang dikalkulasikan dari 150 data High dibagi dengan 313 data data yang diklasifikasikan menjadi data High. Hasil Recall adalah 0.279 yang dikalkulasikan dari 150 data High dibagi dengan 537 data keseluruhan High. 
b. Precision dari data Under adalah 0.565 yang dikalkulasikan dari 255 data Under dibagi dengan 451 data yang diklasifikasikan menjadi data Under. Hasil Recalladalah 0.440 yang dikalkulasikan dari 255 data Under dibagi dengan 580 data keseluruhan Under.

c. Precision dari data Average adalah 0.576 yang dikalkulasikan dari 810 data Average dibagi dengan 1407 data yang diklasifikasikan menjadi data Average. Hasil Recall adalah 0.769 yang dikalkulasikan dari 810 data Average dibagi dengan 1054 data keseluruhan Average.

d. Average Precision dari seluruh data adalah 0.549 dan Average Recall dari seluruh data adalah 0.560 .

\section{Pengujian Split Test 70:30 Tanpa SMOTE}

(1) Accuracy

$\begin{array}{lll}\text { Correctly Classified Instances } & 350 & 53.7634 \% \\ \text { Incorrectly Classified Instances } & 301 & 46.2366 \%\end{array}$

Gambar 4 Accuracy Split Test

Dari gambar di atas mengartikan bahwa data yang diklasifikasikan dengan benar adalah $53.7634 \%$ sedangkan data yang diklasifikasikan secara tidak benar adalah $46.2366 \%$.

(2) Confusion Matrix

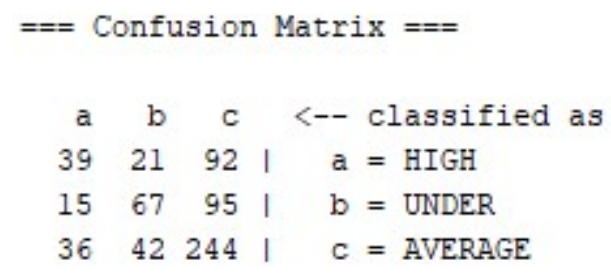

Gambar 5 Confusion Matrix Split Test

Dari gambar confusion matrix 5 dapat dilihat bahwa:

a. 39 data High yang diklasifikasikan menjadi data High, 21 data High yang diklasifikasikan menjadi data Under dan 92 data High yang diklasifikasikan menjadi data Average.

b. 15 data Underyang diklasifikasikan menjadi data High, 67 data Underyang diklasifikasikan menjadi data Under dan 95 data Under yang diklasifikasikan menjadi data Average.

c. 36 data Average yang diklasifikasikan menjadi data High, 42 data Average yang diklasifikasikan menjadi data Under dan 244 data Average yang diklasifikasikan menjadi data Average.

(3) Precision Recall

$\begin{array}{ll}\text { Precision } & \text { Recal1 } \\ 0.433 & 0.257 \\ 0.515 & 0.379 \\ 0.566 & 0.758 \\ 0.521 & 0.538\end{array}$

Gambar 6 Precision Recall Split Test

Dari gambar 6 dapat dijelaskan bahwa:

d. Precision dari data High adalah 0.433 yang dikalkulasikan dari 39 data High dibagi dengan 90 data yang diklasifikasikan menjadi data High. Hasil Recall adalah 0.257 yang dikalkulasikan dari 39 data High dibagi dengan 152 data keseluruhan High. 
e. Precision dari data Under adalah 0.515 yang dikalkulasikan dari 67 data Under dibagi dengan 130 data yang diklasifikasikan menjadi data Under. Hasil Recall adalah 0.440 yang dikalkulasikan dari 67 data Under dibagi dengan 177 data keseluruhan Under.

f. Precision dari data Average adalah 0.566 yang dikalkulasikan dari 244 data Average dibagi dengan 431 data yang diklasifikasikan menjadi data Average. Hasil Recall adalah 0.758 yang dikalkulasikan dari 322 data Average dibagi dengan 1054 data keseluruhan Average.

g. Average Precision dari seluruh data adalah 0.521 dan Average Recall dari seluruh data adalah 0.538 .

\section{Pengujian Cross Validation 10 Folds Menggunakan SMOTE}

(1) Accuracy

$\begin{array}{lll}\text { Correctly Classified Instances } & 2087 & 64.3143 \% \\ \text { Incorrectly Classified Instances } & 1158 & 35.6857 \%\end{array}$

Gambar 7 Accuracy Cross Validation

Dari gambar di atas mengartikan bahwa data yang diklasifikasikan dengan benar adalah $64.3143 \%$ sedangkan data yang diklasifikasikan secara tidak benar adalah $35.6857 \%$.

(2) Confusion Matrix

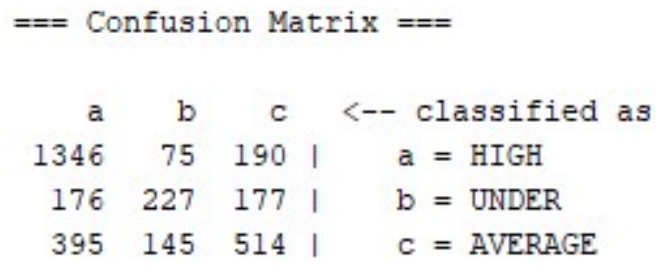

Gambar 8 Confusion Matrix Cross Validation

Dari Gambar confusion matrix 8 dapat dilihat bahwa:

a. 1346 data High yang diklasifikasikan menjadi data High, 75 data High yang diklasifikasikan menjadi data Under dan 190 data High yang diklasifikasikan menjadi data Average.

b. 176 data Under yang diklasifikasikan menjadi data High, 227 data Under yang diklasifikasikan menjadi data Under dan 177 data Underyang diklasifikasikan menjadi data Average.

c. 395 data Average yang diklasifikasikan menjadi data High, 145 data Average yang diklasifikasikan menjadi data Under dan 514 data Average yang diklasifikasikan menjadi data Average.

(3) Precision Recall

$\begin{array}{ll}\text { Precision } & \text { Recal1 } \\ 0.702 & 0.836 \\ 0.508 & 0.391 \\ 0.583 & 0.488 \\ 0.629 & 0.643\end{array}$

Gambar 9 Precision Recall Cross Validation 
Dari gambar 9 dapat dijelaskan bahwa:

a. Precision dari data High adalah 0.602 yang dikalkulasikan dari 1346 data High dibagi dengan 1917 data yang diklasifikasikan menjadi data High. Hasil Recalladalah 0.836 yang dikalkulasikan dari 1346 data High dibagi dengan 1611 data keseluruhan High.

b. Precision dari data Under adalah 0.508 yang dikalkulasikan dari 227 data Under dibagi dengan 447 data yang diklasifikasikan menjadi data Under. Hasil Recall adalah 0.391 yang dikalkulasikan dari 227 data Under dibagi dengan 580 data keseluruhan Under.

c. Precision dari data Average adalah 0.583 yang dikalkulasikan dari 514 data Average dibagi dengan 881 data yang diklasifikasikan menjadi data Average. Hasil Recall adalah 0.488 yang dikalkulasikan dari 514 data Average dibagi dengan 1054 data keseluruhan Average.

d. Average Precision dari seluruh data adalah 0.629 dan Average Recall dari seluruh data adalah 0.643.

\section{Pengujian Split Test 70:30 Menggunakan SMOTE}

(1) Accuracy

$\begin{array}{lll}\text { Correctly Classified Instances } & 599 & 61.5622 \% \\ \text { Incorrectly Classified Instances } & 374 & 38.4378 \%\end{array}$

Gambar 10 Accuracy Split Test

Dari gambar di atas mengartikan bahwa data yang diklasifikasikan dengan benar adalah 61.5622 $\%$ sedangkan data yang diklasifikasikan secara tidak benar adalah $38.4378 \%$.

(2) Confusion Matrix

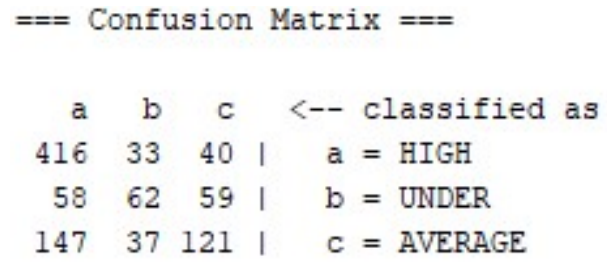

\section{Gambar 11 Confusion Matrix Split Test}

Dari Gambar confusion matrix 4.28 dapat dilihat bahwa:

a. 416 data High yang diklasifikasikan menjadi data High, 33 data High yang diklasifikasikan menjadi data Under dan 40 data High yang diklasifikasikan menjadi data Average.

b. 58 data Underyang diklasifikasikan menjadi data High, 62 data Underyang diklasifikasikan menjadi data Under dan 59 data Under yang diklasifikasikan menjadi data Average.

C. 147 data Average yang diklasifikasikan menjadi data High, 37 data Average yang diklasifikasikan menjadi data Under dan 121 data Average yang diklasifikasikan menjadi data Average.

(3) Precision Recall

$\begin{array}{ll}\text { Precision } & \text { Recall } \\ 0.702 & 0.836 \\ 0.508 & 0.391 \\ 0.583 & 0.488 \\ 0.629 & 0.643\end{array}$

Gambar 12 Precision Recall Cross Validation 
Prediksi Indeks Prestasi Mahasiswa Yang Berkuliah Sambil Bekerja Di Universitas Advent Indonesia Dengan Menggunakan Metode Decision Tree C4.5 Dan SMOTE

Dari gambar 12 dapat dijelaskan bahwa:

a. Precision dari data High adalah 0.702 yang dikalkulasikan dari 416 data High dibagi dengan 612 data yang diklasifikasikan menjadi data High. Hasil Recall adalah 0.836 yang dikalkulasikan dari 416 data High dibagi dengan 489 data keseluruhan High.

b. Precision dari data Under adalah 0.470 yang dikalkulasikan dari 62 data Under dibagi dengan 132 data yang diklasifikasikan menjadi data Under. Hasil Recalladalah 0.346 yang dikalkulasikan dari 62 data Under dibagi dengan 179 data keseluruhan Under.

c. Precision dari data Average adalah 0.550 yang dikalkulasikan dari 121 data Average dibagi dengan 220 data yang diklasifikasikan menjadi data Average. Hasil Recall adalah 0.397 yang dikalkulasikan dari 121 data Average dibagi dengan 305 data keseluruhan Average.

d. Average Precision dari seluruh data adalah 0.595 dan Average Recall dari seluruh data adalah 0.616 .

\section{Kesimpulan}

Hasil analisa kurva ROC dengan hasil dari 0.676 menjadi 0.770 , yang berada dalam rentang $0.70-$ 0.80 yang masuk kedalam tingkat diagnose fair classification. Dapat disimpulkan bawa terdapat pengaruh berkuliah sambil bekerja yang cukup kuat terhadap indeks prestasi mahasiswa. Dengan atribut yang paling mempengaruhi yang diurutkan dari hasil penghitungan entropy adalah Jenis Kelamin dengan hasil entropy 0.8, Jumlah SKS hasil entropy 0.1, Jurusan hasil entropy 0.06, Departemen Kerja hasil entropy0.006, Umur dengan hasil entropy 0.001, Jam Kerja hasil entropy 0.0017 dan Tempat Tinggal hasil entropy 0.0011.

\section{Daftar Pustaka}

[1] Andriyan, David. (2016). Indeks Prestasi Komulatif Mahasiswa Ditinjau dari Strategi Belajar dan Keaktifan Berorganisasi pada Mahasiwa Pendidikan Akuntansi Universitas Muhammadiyah Surakarta tahun 2014. [Online]. Available: http://davidandriyan.blogspot.co.id/2016/07/proposal-penelitian-dengan-judulindeks.html [5 April 2018]

[2] B. Rossi, S. Itasia, and A, Farit, "Penerapan Synthetic Minority Oversampling Technique (SMOTE) Terhadap Data Tidak Seimbang Pada Pembuatan Model Komposisi Jamu," vol. 1, no. 1, 2013. Diakses pada: Maret, 16, 2019. [Online]. Tersedia di: http://dx.doi.org/10.29244/xplore.v1i1.12424

[3] Berry, Michael J.A dan Linoff, Gordon S (2004). Data Mining Techniques For Maketing, Sales, Customer Relationship Management Second Edition. United States of America: Wiley Publishing, Inc.

[4] Defiyanti, Sofi (2014). Perbandingan: Prediksi Prestasi Belajar Mahasiswa Menggunakan Teknik Data Mining (Study Kasus Fasilkom UNSIKA). Makasar: KNSI.

[5] Larose, D. T. (2005). Discovering Knowledge in Data. New Jersey: John Willey \&Sons, Inc.

[6] Lestari, Fenti (2016). Pengaruh Lingkungan Keluarga Dan Fasilitas Belajar Terhadap Motivasi Belajar Dan Hasil Belajar Siswa KElas XI IPS Pada Mata Pelajaran Ekonomi DI SMAN 2 Kebumen Tahun Pelajaran 2015/2016. Yogyakarta: Universitas Negri Yogyakarta.

[7] Putri, Ratna P.S dan Waspada, Indra (2018). Penerapan Algoritma C4.5 Pada Aplikasi Prediksi Kelulusan Mahasiswa Prodi Informatika. Semarang: Jurnal Ilmu Komputer dan Informatika 